\title{
Cohort Study
}

\section{e Concordant Pain Provocation During Transforaminal Epidural Steroid Injection for Lumbosacral Radiculopathy: Effect on Pain Outcome and Predictive Factors}

\author{
Zachary McCormick, MD'1, Shana Margolis, MD'1, Kate Temme, MD², Evan Rivers, DO³, \\ Scott A. Cameron, MD', Matthew C. Smith, MD5, Ashley Rohr, MD ${ }^{6}$, Emily Zander, MD7, \\ Cynthia Garvan, $\mathrm{PhD}^{8}$, David J. Kennedy, $\mathrm{MD}^{9}$, and Christopher Plastaras, $\mathrm{MD}^{2}$
}

From: ' ${ }^{2}$ epartment of PM\&R, Northwestern University/

The Rehabilitation Institute of Chicago, Chicago, IL.; ${ }^{2}$ Department of PM\&R, University of Pennsylvania, Philadelphia, PA; ${ }^{3}$ Department of Neurosurgery, University of New Mexico, Albuquerque, NM; ${ }^{4}$ Department of Pediatrics, Cincinnati Children's Hospital Medical Center, Cincinnati, OH; ${ }^{5}$ Department of Orthopaedic

Surgery, Medical College of Wisconsin, Milwaukee, WI; ${ }^{6}$ Department of Ophthalmology, University of Chicago, Chicago, IL; ${ }^{7}$ Department of Pediatrics, Northwestern University/ Lurie Children's Hospital, Chicago, IL; ${ }^{8}$ College of Nursing, University of Florida, Gainesville, FL;

9 Department of Orthopaedics, Stanford University, Palo Alto, CA.

Address Correspondence: Zack McCormick, MD Department of Physical Medicine and Rehabilitation

Rehabilitation Institute of Chicago

Northwestern University Chicago, Illinois E-mail:zmccormi@gmail.com

See Page E26 for Disclaimer and Conflict of Interest statements.

Manuscript received:07-17-2014 Revised manuscript received: 09-15-2014

Accepted for publication: 10-13-2014

Free full manuscript: www.painphysicianjournal.com
Background: Anecdotal report suggests that provocation of pain during epidural steroid injection (ESI) that is concordant with typical radicular symptoms predicts pain outcome following injection. However, limited evidence exists that substantiates this theory. Additionally, there is a paucity of literature investigating factors associated with the provocation of pain during ESI.

Objectives: The goal of this study was to determine whether provocation of concordant radicular pain during transforaminal ESI predicts pain relief immediately after injection and at short-term follow-up. Demographic, radiologic, and procedural factors associated with the pain provocation and pain outcomes at immediate and short-term follow-up were also investigated.

Study Design: Longitudinal cohort study.

Setting: Urban academic outpatient interventional spine clinics.

Methods: Adults who underwent a fluoroscopically guided transforaminal ESI without sedation between January 1, 2006, and October 29, 2007, for the treatment of lumbosacral radicular pain were included in this study. The relationships between provocation of concordant pain, immediate post-injection, and follow-up visual analogue scale (VAS) pain scores, as well as with demographic, radiologic, and procedural factors were determined using chi-square/Fisher's exact tests for categorical variables and t-tests or ANOVA for numerical variables.

Results: One thousand twenty one patients, 42.4\% (433) male/57.6\% (588) female, with a mean (SD) age of 54.1 (16.7) years were included in the study. Concordant pain provocation did not predict the magnitude of pain reduction $(P=0.9255)$ or the frequency of achieving $>$ $50 \%$ pain relief $(P=0.7449)$ at short-term follow-up. Radiologic evidence of foraminal stenosis or nerve root impingement $(P<0.0001)$ and the lack of a medial-superior contrast flow pattern $(P=$ 0.0199 ) were associated with a greater frequency of pain provocation during transforaminal ESI.

Limitations: This study is primarily limited by possible selection bias given that patients who did not follow-up in the clinic could not be studied, and an incomplete follow-up rate $(66 \%)$. Conclusions regarding subacute and long-term pain outcomes cannot be determined from this study as only short-term data were available.

Conclusions: Provocation of concordant radicular pain does not predict pain relief at short-term follow-up after a transforaminal ESI. Foraminal stenosis, nerve root impingement, and lack of a medial-superior contrast flow pattern are associated with pain during the transforaminal ESI. Thus, clinicians should be aware of these radiologic and procedural risk factors for inciting pain during transforaminal ESI.

Key words: Epidural steroid injection, lumbar, radicular pain, outcomes, prognostic

Pain Physician 2015; 18:E19-E26 
E pidural steroid injections (ESIs) are frequently used in the nonsurgical management of lumbosacral radicular pain (1). During lumbosacral ESIs, patients commonly report provocation of sensations concordant with their presenting radicular symptoms (2-13). Provocation of concordant radicular pain during ESI is reported to predict pain relief at short-term follow-up, but this has only been observed in 2 small to medium-size studies limited to interlaminar ESIs $(14,15)$. One small pilot study of transforaminal ESIs found no association between provocation of concordant pain and the magnitude of pain relief at short-term follow-up (16).

No study has investigated factors associated with the provocation of concordant radicular pain during ESI, though 3 studies have investigated elements associated with provocation of pain without comment on concordance or discordance with typical radicular symptoms. Perrot et al (17) found that procedural pain was associated with the presence of pain related to the underlying condition during the week prior and to greater pre-injection anxiety. Tekaya et al (18) found that procedural pain was associated with younger age, lack of co-morbidities, and greater pre-injection pain. Notably, both studies failed to report whether the spinal injections studied accessed the epidural space or, if so, what approach was taken. Park and Lee (19) found that the amount of pressure applied to the syringe plunger during transforaminal ESI was not associated with a greater frequency of pain provocation during injection.

The aim of this study was to determine whether provocation of concordant radicular pain during transforaminal ESI predicts greater pain relief at short-term follow-up. Secondary goals were to assess whether demographic, radiologic, or procedural factors were associated with the provocation of concordant radicular pain during the injection.

\section{Methods}

This was a longitudinal cohort study, approved by the Northwestern University Institutional Review Board. The study included individuals of 18 years or greater who underwent a contrast enhanced fluoroscopically guided transforaminal ESI between January 1, 2006, and October 29, 2007, at the Rehabilitation Institute of Chicago (RIC) Spine and Sports Rehabilitation Center or RIC at Herrin Hospital. The general indication for transforaminal ESI in this cohort was lumbosacral radicular pain that had failed to respond to conservative treatment and continued to cause functional limitations. All injections were ordered and performed by board-certified physical medicine \& rehabilitation physicians, with additional board certification in either pain medicine or sports medicine.

Clinical data were entered into a discrete structured clinical database (RICPLAS - Rehabilitation Institute of Chicago Physiatric Log \& Analysis System) as a routine method of clinical documentation to be placed in the hospital medical record. The treating physician entered all data using structured drop down menu options to facilitate standardized reporting. Variables including age, gender, specific radiologic diagnosis at the level of injection, whether the spine pathology presumed to be responsible for clinical symptoms was present at the level of injection, needle length, volume of contrast and local anesthetic injected, contrast flow pattern, presence of intravascular contrast uptake, involvement of a trainee in the procedure, and pre-injection, immediate post-injection, and follow-up pain score using a visual analogue scale (VAS) were entered into the database. Contrast flow pattern was categorized as either "superiomedial" or "other," which included any other contrast pattern such as inferomedial, peripheral more than medial, etc. Trainee involvement was separated by residents, fellows, and attending physicians who were being trained to perform transforaminal ESIs by the senior attending physicians with additional board certification in either pain medicine or sports medicine in the practice. Deidentified data were extracted from the clinical database (RICPLAS) using queries in Microsoft SQL Server 2000 and Microsoft Access 2003. Electronic medical chart review was performed to capture follow-up visit data.

Injections were performed using a subpedicular transforaminal technique (20). The patient was positioned prone. The skin was prepped using sterile technique. The fluoroscope was positioned to provide an oblique view to identify the subpedicular space at the level of intended injection. One percent lidocaine (preservative-free) was used for skin and soft tissue analgesia. A sterile 22 gauge 3.5-, 5-, or 7-inch spinal needle was positioned at the superior aspect of the neural foramen above the exiting spinal nerve. Needle placement was confirmed by anterior-posterior, oblique, and lateral fluoroscopy. Between 0.2 and 0.5 $\mathrm{mL}$ of Isovue 300 contrast dye was injected through microbore tubing during live fluoroscopy. If there was intravascular uptake, the needle was repositioned un- 
til no intravascular uptake was observed and until an epidural flow pattern was present. Subsequently, 1.5 $-2 \mathrm{~mL}$ of $1 \%$ lidocaine was injected as an anesthetic test dose. After waiting $1-2$ minutes and assuring no complications, corticosteroid (betamethasone [6 $\mathrm{mg} /$ $\mathrm{mL}$ ] or triamcinolone [40 $\mathrm{mg} / \mathrm{mL}]$ ) was then injected through microbore tubing. Injectate volumes varied depending on the number of sites injected. For unilateral single level injections, $2 \mathrm{~mL}$ of $1 \%$ lidocaine and $2 \mathrm{~mL}$ of corticosteroid were used. For unilateral 2 level or single level bilateral injections, $1.5 \mathrm{~mL}$ of $1 \%$ lidocaine and $1 \mathrm{~mL}$ of corticosteroid were used at each injection site. Bilateral procedures were chosen for patients with bilateral symptoms. Two-level unilateral procedures were chosen for patients with multilevel disease. All patients in this cohort received either 40 $\mathrm{mg}$ triamcinolone or $12 \mathrm{mg}$ of betamethasone, regardless of whether the injection was performed at one site or 2. No patients in this cohort received injections targeting more than 2 sites.

\section{Assessment of Provocation of Concordant Pain}

The following script was used:

- At the time of contrast injection, the individual was asked: "are you having pain?"

- If the answer was "no," a drop-down box indicating "typical symptoms NOT provoked" was entered into the clinical database.

- If the answer was "yes," the individual was instructed: "Without pointing, tell me if it is in the usual location of your typical pain."

- If the response given was "yes," a drop-down box in the clinical database was selected that indicated "typical symptoms provoked" (concordant pain provocation).

- If the answer was "no," a drop-down box indicating "atypical symptoms provoked" was entered into the clinical database.

\section{Statistical Analysis}

Data were checked for implausible values and distributional form. In order to illustrate the demographic, radiologic, and procedural characteristics of the study sample, we calculated means and standard deviations for continuous variables and percentages for categorical variables. A patient's first procedure during the study timeframe was included in statistical analyses to ensure that observations were independent. Patients were classified as having greater or less than
$50 \%$ reduction in pain from pre-injection to follow-up pain as measured by VAS. The relationship between demographic, radiologic, and procedural details with pain provocation during injection, pre-injection, immediate post-injection, and follow-up pain scores were determined using chi-square or Fisher's exact tests for categorical variables and t-tests or ANOVA for numerical variables. Wilson's exact method was used for confidence interval computation. Data were analyzed using SAS version 9.3 (Cary, NC). The level of significance was set at 0.05 . Two-sided testing was used for all hypothesis testing.

\section{Results}

The study included 1,021 individuals, 42.4\% (433) male/57.6\% (588) female, with a mean (SD) age of 54.1 (16.7) years. Demographic, radiologic, and procedural details are included in Table 1. Patients fell into 5 groups of follow-up: 1: none, $34.0 \%$ (347); 2 : less than one week, $2.8 \%$ (29); 3 : between one and 4 weeks, $51.2 \%$ (522); 4 : more than 4 weeks, $11.7 \%$ (119); and 5: unknown duration, $0.3 \%$ (3). The mean (SD) pre-injection, immediate post-injection, and follow-up VAS were 6.0 (2.2), 2.7 (2.9), and 4.3 (2.3), respectively. The percentage of patients with greater than $50 \%$ reduction in pain at follow-up was $31.4 \%$ $(95 \% \mathrm{Cl}=[28 \%, 35 \%])$.

Table 2 shows the relationship between demographic, radiologic, and procedural factors with provocation of concordant pain during injection. Concordant pain was provoked in 688 (68.4\%) of injections, while no concordant pain was provoked in 318 (31.6\%). Radiologic diagnosis of spinal pathology at the level of injection was significantly associated with concordant pain during injection $(P<0.0001)$. Injections in all diagnoses except degenerative disc disease were more likely to lead to concordant pain provocation than no concordant pain provocation. Individuals with foraminal stenosis followed by nerve root impingement most frequently reported concordant pain provocation. There was a higher chance of reporting concordant pain during injection when a medial-superior contrast flow pattern was not obtained $(P=0.0199)$. No other investigated clinical factors were significantly associated with concordant pain provocation during injection.

Table 3 depicts the relationship between demographic, radiologic, and procedural factors with preinjection, immediate post-injection, and follow-up pain as measured by VAS. Younger age was signifi- 
Table 1. Demographic, radiologic, and procedural information for study participants.

\begin{tabular}{|c|c|}
\hline Total Number of Study Participants & 1,021 \\
\hline Demographic Factors & $\begin{array}{c}\text { Mean (SD) } \\
\text { or } \%(n)\end{array}$ \\
\hline Age, years & $54.1(16.7)$ \\
\hline $\begin{array}{l}\text { Gender } \\
\text { Female } \\
\text { Male }\end{array}$ & $\begin{array}{l}57.6 \%(588) \\
42.4 \%(433)\end{array}$ \\
\hline \multicolumn{2}{|l|}{ Radiologic Factors } \\
\hline $\begin{array}{l}\text { Specific Radiologic Diagnosis at Level of Injection } \\
\text { Central stenosis } \\
\text { Foraminal stenosis } \\
\text { Degenerative disc disease } \\
\text { Disc herniation } \\
\text { Spondylolisthesis } \\
\text { Nerve root impingement } \\
\text { Multiple findings }\end{array}$ & $\begin{array}{c}4.6 \%(47) \\
2.0 \%(20) \\
4.1 \%(42) \\
9.8 \%(100) \\
1.5 \%(15) \\
25.7 \%(262) \\
52.4 \%(534)\end{array}$ \\
\hline \multicolumn{2}{|l|}{ Procedure Characteristics } \\
\hline $\begin{array}{l}\text { Needle length (inches) } \\
3.5 \\
5.0 \\
7.0\end{array}$ & $\begin{array}{c}73.7 \%(751) \\
25.0 \%(255) \\
1.3 \%(13)\end{array}$ \\
\hline $\begin{array}{l}\text { Injectate Volume }(\mathrm{mL}) \\
\text { Contrast } \\
\text { Local anesthetic }\end{array}$ & $\begin{array}{l}1.43(0.76) \\
2.15(0.42)\end{array}$ \\
\hline $\begin{array}{l}\text { Medial \& Superior Contrast Pattern } \\
\text { Yes } \\
\text { No }\end{array}$ & $\begin{array}{c}92.1 \%(935) \\
7.9 \%(80)\end{array}$ \\
\hline $\begin{array}{l}\text { Intravascular uptake } \\
\text { Yes } \\
\text { No }\end{array}$ & $\begin{array}{c}7.1 \%(38) \\
92.9 \%(500)\end{array}$ \\
\hline $\begin{array}{l}\text { Trainee Involved } \\
\text { No } \\
\text { Physician } \\
\text { Fellow } \\
\text { Resident }\end{array}$ & $\begin{array}{c}46.7 \%(476) \\
8.6 \%(88) \\
41.6 \%(424) \\
3.1 \%(32)\end{array}$ \\
\hline \multicolumn{2}{|l|}{ Reported Pain } \\
\hline Pre-injection VAS & $6.0(2.2)$ \\
\hline Immediate post-injection VAS & $2.7(2.9)$ \\
\hline Follow-up VAS & $4.3(2.3)$ \\
\hline $\begin{array}{l}\text { Concordant Pain Provoked During Injection } \\
\text { Yes } \\
\text { No }\end{array}$ & $\begin{array}{l}68.4 \%(688) \\
31.6 \%(318)\end{array}$ \\
\hline \multicolumn{2}{|l|}{ Follow-up Interval Post-injection } \\
\hline $\begin{array}{l}\text { No follow-up } \\
\text { Less than } 1 \text { week } \\
\text { Between } 1 \text { and } 4 \text { weeks } \\
\text { More than } 4 \text { weeks } \\
\text { Unknown }\end{array}$ & $\begin{array}{c}34.0 \%(347) \\
2.8 \%(29) \\
51.2 \%(522) \\
11.7 \%(119) \\
0.3 \%(3)\end{array}$ \\
\hline
\end{tabular}

cantly associated with higher pre-injection pain ( $P=$ $0.0312)$. After adjusting for pre-injection VAS pain score, men $(P=0.0434)$, a smaller volume of local anesthetic in the injectate $(P=0.0208)$, and concordant pain provocation during injection $(P=0.0107)$ were significantly associated with higher immediate post-injection VAS pain scores. After adjusting for preinjection VAS pain score, greater post-injection VAS pain score $(P<0.0001)$ was significantly associated with greater pain reported at follow-up. No other investigated clinical factors were significantly associated with the magnitude of reported pain scores at these 3 time points.

Table 4 illustrates the relationship of demographic, radiologic, and procedural factors between greater or less than $50 \%$ reduction in pain from pre-injection to follow-up pain as measured by VAS. There was no statistically significantly difference between the variables among individuals who experience greater or less than a $50 \%$ reduction in pain at follow-up.

\section{Discussion}

While popular anecdotal belief proposes that provocation of concordant radicular pain predicts a positive outcome after ESI for the treatment of radicular pain, our data contradicts this theory. This finding is consistent with our previously published data (16). Also consistent with this study, El-Yahchouchi et al (21) found that immediate post-procedure pain after lumbosacral transforaminal ESI was only weakly associated with short-term pain and functional outcome, though concordant pain provocation was not specifically investigated by these authors. In contrast, Candido et al (14) and Sinofsky et al (15) found concordant radicular symptom provocation to be associated with a greater magnitude of pain relief after ESI. Both of these studies investigated interlaminar ESIs, whereas this study, Plastaras et al (16), and El-Yahchouchi et al (21) investigated transforaminal ESIs. Pain at follow-up is related to immediate post-procedural pain even after adjusting for pre-procedural pain. This may suggest a difference in the prognostic value of concordant pain provocation with different approaches to ESI. However, it is not clear why interlaminar and transforaminal approaches to ESI would differ in this regard. Differences in the study sample may account for this discrepancy, where those in this study only received an 
Table 2. Relationships between concordant pain provoked during procedure and patient and procedure factors.

\begin{tabular}{|c|c|c|c|}
\hline Demographic Factors & $\begin{array}{c}\text { Concordant Pain Provoked } \\
\text { during Injection } \\
\text { Mean (SD) or \% (n) }\end{array}$ & $\begin{array}{l}\text { No Concordant Pain during } \\
\text { Injection } \\
\text { Mean (SD) or \% (n) }\end{array}$ & $P$-value \\
\hline Age & $54.1(16.6)$ & $54.4(17.0)$ & 0.7910 \\
\hline $\begin{array}{l}\text { Gender } \\
\text { Female } \\
\text { Male }\end{array}$ & $\begin{array}{l}69.6 \%(403) \\
66.7 \%(285)\end{array}$ & $\begin{array}{l}30.4 \%(176) \\
33.3 \%(142)\end{array}$ & .3352 \\
\hline \multicolumn{4}{|l|}{ Radiologic Factors } \\
\hline $\begin{array}{l}\text { Specific Radiologic Diagnosis at Level of Injection } \\
\text { Central stenosis } \\
\text { Foraminal stenosis } \\
\text { Degenerative disc disease } \\
\text { Disc herniation } \\
\text { Spondylolisthesis } \\
\text { Nerve root impingement } \\
\text { Multiple diagnoses }\end{array}$ & $\begin{array}{c}60.9 \%(28) \\
80.0 \%(16) \\
28.2 \%(11) \\
61.2 \%(60) \\
60.0 \%(9) \\
74.4 \%(195) \\
70.2 \%(369)\end{array}$ & $\begin{array}{c}39.1 \%(18) \\
20.0 \%(4) \\
71.8 \%(28) \\
38.8 \%(38) \\
40.0 \%(6) \\
25.6 \%(67) \\
29.9 \%(157)\end{array}$ & $<0.0001$ \\
\hline \multicolumn{4}{|l|}{ Procedure Characteristics } \\
\hline $\begin{array}{l}\text { Needle Length (inches) } \\
3.5 \\
5.0 \\
7.0\end{array}$ & $\begin{array}{l}68.7 \%(507) \\
67.5 \%(172) \\
66.7 \%(8) \\
\end{array}$ & $\begin{array}{c}31.3 \%(231) \\
32.6 \%(83) \\
33.3 \%(4)\end{array}$ & .9265 \\
\hline $\begin{array}{l}\text { Volume of Injectate }(\mathrm{mL}) \\
\text { Contrast } \\
\text { Local anesthetic }\end{array}$ & $\begin{array}{l}1.44(0.76) \\
2.14(0.42)\end{array}$ & $\begin{array}{l}1.40(0.73) \\
2.15(0.42)\end{array}$ & $\begin{array}{l}.4538 \\
.8843\end{array}$ \\
\hline $\begin{array}{l}\text { Medial \& Superior Contrast Pattern } \\
\text { Yes } \\
\text { No }\end{array}$ & $\begin{array}{c}67.4 \%(622) \\
80.0 \%(64)\end{array}$ & $\begin{array}{r}32.6 \%(301) \\
20.0 \%(16)\end{array}$ & .0199 \\
\hline $\begin{array}{l}\text { Trainee Involved } \\
\text { No } \\
\text { Physician } \\
\text { Fellow } \\
\text { Resident }\end{array}$ & $\begin{array}{l}65.8 \%(310) \\
65.9 \%(58) \\
71.6 \%(297) \\
71.9 \%(23)\end{array}$ & $\begin{array}{c}34.2 \%(161) \\
34.1 \%(30) \\
28.4 \%(118) \\
28.1 \%(9)\end{array}$ & .2828 \\
\hline \multicolumn{4}{|l|}{ Reported Pain } \\
\hline Pre-injection VAS & $6.0(2.2)$ & $5.9(2.2)$ & .3744 \\
\hline
\end{tabular}

ESI if they had persistent pain and functional deficits after failed conservative management. Thus this study sample may represent patients with more refractory radicular pain compared to that studied by Candido et al (14) and Sinofsky et al (15).

As expected, this study confirmed that patients experience less pain reduction in the immediate period after injection if concordant pain is provoked during the procedure. Thus, these findings suggest that there is no advantage to provoking pain during transforaminal ESI since this, in itself, is painful and pain will persist during the immediate post-injection period.

Pain provocation during the procedure was most frequent when radiologic evidence of neural foraminal stenosis or spinal nerve root impingement was pres- ent at the level of injection $(P<0.0001)$. It is intuitive that pain is more likely to be provoked when injecting volume near a nerve root with little surrounding space or when it is already compressed as opposed to injecting into an area in which there is plentiful space for dispersion of volume away from a symptomatic nerve root. However, to the best of our knowledge, this study is the first to document this observation.

Provocation of concordant pain was more likely to occur when the contrast pattern was inconsistent with medial and superior flow $(P=0.0199)$. One implication of this finding is that clinicians should attempt to avoid a non-medial and superior contrast flow pattern before injection of corticosteroid in order to reduce the chance of provoking pain during the procedure. However, the clinicians who performed injections for 
Pain Physician: January/February 2015; 18:E19-E26

Table 3. Relationships between demographic, radiologic, procedural characteristics, and reported VAS pre-injection, immediately post-injection, and at short-term follow-up.

\begin{tabular}{|c|c|c|c|c|c|c|}
\hline & $\begin{array}{c}\text { Pre- } \\
\text { injection } \\
\text { VAS } \\
\text { Mean (SD) }\end{array}$ & $\begin{array}{c}\text { Immediate } \\
\text { Post-injection } \\
\text { VAS } \\
\text { Mean (SD) }\end{array}$ & $\begin{array}{c}\text { Follow-up } \\
\text { VAS } \\
\text { Mean } \\
\text { (SD) }\end{array}$ & \begin{tabular}{|c|} 
Relationship \\
Pre-injection \\
VAS \\
$P$-value \\
\end{tabular} & $\begin{array}{l}\text { Relationship } \\
\text { Immediate } \\
\text { Post-injection } \\
P \text {-value(1) }\end{array}$ & $\begin{array}{c}\text { Relationship } \\
\text { Follow-up VAS } \\
P \text {-value (1) }\end{array}$ \\
\hline \multicolumn{7}{|l|}{\begin{tabular}{|l} 
Demographic Factors \\
\end{tabular}} \\
\hline Age (correlation) & 0.07 & 0.02 & 0.05 & .0312 & .8411 & .4405 \\
\hline $\begin{array}{l}\text { Gender } \\
\text { Female } \\
\text { Male }\end{array}$ & $\begin{array}{l}6.0(2.2) \\
5.9(2.2)\end{array}$ & $\begin{array}{l}2.6(2.9) \\
2.9(2.8)\end{array}$ & $\begin{array}{l}4.3(2.4) \\
4.2(2.2)\end{array}$ & .2923 & .0434 & .7890 \\
\hline \multicolumn{7}{|l|}{ Radiologic Factors } \\
\hline $\begin{array}{l}\text { Specific Radiologic Diagnosis at Level } \\
\text { of Injection } \\
\text { Central stenosis } \\
\text { Foraminal stenosis } \\
\text { Degenerative disc disease } \\
\text { Disc herniation } \\
\text { Spondylolisthesis } \\
\text { Nerve root impingement } \\
\text { Multiple diagnoses }\end{array}$ & $\begin{array}{l}6.6(2.3) \\
5.9(2.2) \\
5.7(1.8) \\
6.0(2.2) \\
5.7(2.9) \\
5.9(2.0) \\
6.0(2.2)\end{array}$ & $\begin{array}{l}3.3(3.7) \\
2.8(3.2) \\
2.8(2.8) \\
2.6(2.9) \\
3.3(2.9) \\
2.8(2.9) \\
2.7(2.8)\end{array}$ & $\begin{array}{l}4.8(2.3) \\
4.7(2.5) \\
4.5(2.2) \\
4.3(2.2) \\
3.0(1.8) \\
4.1(2.3) \\
4.3(2.4)\end{array}$ & .5088 & .9045 & .4801 \\
\hline \multicolumn{7}{|l|}{ Procedure Characteristics } \\
\hline $\begin{array}{l}\text { Needle Length (inches) } \\
3.5 \\
5.0 \\
7.0\end{array}$ & $\begin{array}{l}5.9(2.2) \\
6.2(2.1) \\
5.6(2.2)\end{array}$ & $\begin{array}{l}2.8(2.9) \\
2.5(2.9) \\
3.4(3.5)\end{array}$ & $\begin{array}{l}4.3(2.4) \\
4.2(2.2) \\
3.8(2.2)\end{array}$ & .2441 & .1028 & .7165 \\
\hline $\begin{array}{l}\text { Injectate Volume (correlations) } \\
\text { Total contrast } \\
\text { Total local anesthetic }\end{array}$ & $\begin{array}{c}0.03 \\
-0.02\end{array}$ & $\begin{array}{c}0.04 \\
-0.10 \\
\end{array}$ & $\begin{array}{l}0.01 \\
0.02 \\
\end{array}$ & $\begin{array}{r}.2664 \\
.4997 \\
\end{array}$ & $\begin{array}{r}.2095 \\
.0208 \\
\end{array}$ & $\begin{array}{r}.6078 \\
.3965 \\
\end{array}$ \\
\hline $\begin{array}{l}\text { Medial \& Superior Contrast Pattern } \\
\text { Yes } \\
\text { No }\end{array}$ & $\begin{array}{l}6.0(2.1) \\
6.0(2.4)\end{array}$ & $\begin{array}{l}2.7(2.9) \\
2.9(2.8)\end{array}$ & $\begin{array}{l}4.3(2.3) \\
4.2(2.4)\end{array}$ & .9796 & .6364 & .9245 \\
\hline $\begin{array}{l}\text { Intravascular Uptake } \\
\text { Yes } \\
\text { No }\end{array}$ & $\begin{array}{l}6.1(2.1) \\
6.0(2.2)\end{array}$ & $\begin{array}{l}2.3(2.5) \\
2.7(2.9)\end{array}$ & $\begin{array}{l}4.1(2.1) \\
4.3(2.3)\end{array}$ & .7085 & .2196 & .4043 \\
\hline $\begin{array}{l}\text { Trainee Involved } \\
\text { No } \\
\text { Physician } \\
\text { Fellow } \\
\text { Resident }\end{array}$ & $\begin{array}{l}5.9(2.2) \\
5.8(2.2) \\
6.1(2.1) \\
5.9(2.5)\end{array}$ & $\begin{array}{l}2.7(2.8) \\
2.8(2.9) \\
2.7(3.0) \\
2.8(3.0)\end{array}$ & $\begin{array}{l}4.1(2.4) \\
4.1(2.3) \\
4.5(2.3) \\
4.2(2.5)\end{array}$ & .3082 & .8766 & .3024 \\
\hline \multicolumn{7}{|l|}{ Reported Pain } \\
\hline Pre-injection VAS (correlation) & NA & 0.25 & 0.39 & NA & $<0.0001$ & $<0.0001$ \\
\hline Post-injection VAS (correlation) & NA & NA & 0.17 & NA & NA & .0213 \\
\hline $\begin{array}{l}\text { Concorant Pain provoked during } \\
\text { injection } \\
\text { Yes } \\
\text { No }\end{array}$ & $\begin{array}{l}6.0(2.2) \\
5.9(2.2)\end{array}$ & $\begin{array}{l}2.9(2.9) \\
2.4(2.7)\end{array}$ & $\begin{array}{l}4.3(2.3) \\
4.3(2.3)\end{array}$ & .3744 & .0107 & .9255 \\
\hline
\end{tabular}

P-value after adjusting for pre-injection VAS

this study cohort aimed to obtain a medial and superior flow pattern with every injection. Thus, the fact that provocation of pain occurred with greater frequency when a medial and superior contrast pattern was not obtained may indicate the presence of unmeasured factors that prevent attainment of this contrast flow pattern goal and simultaneously increase the chances of provoking pain during an injection. For example, aberrant flow patterns could be related to various anatomical factors including a redundant zygapophysial joint capsule, foraminal or lateral recess stenosis, or a large foraminal disc herniation. The lack of a me- 
Concordant Pain Provocation during Transforaminal Epidural Steroid Injection

Table 4. Relationships between demographic, radiologic, procedural characteristics, and follow-up outcome.

\begin{tabular}{|c|c|c|c|}
\hline & $\begin{array}{c}<50 \% \\
\text { Improvement } \\
\text { Mean (SD) } \\
\text { or n (\%) }\end{array}$ & $\begin{array}{c}\geq 50 \% \text { Improvement } \\
\text { Mean (SD) } \\
\text { or n }(\%)\end{array}$ & $P$-value \\
\hline \multicolumn{4}{|l|}{ Demographic Factors } \\
\hline Age & $54.5(17.2)$ & $54.6(15.6)$ & .9390 \\
\hline $\begin{array}{l}\text { Gender } \\
\text { Female } \\
\text { Male }\end{array}$ & $\begin{array}{l}222(68.3 \%) \\
150(59.1 \%) \\
\end{array}$ & $\begin{array}{l}103(31.7 \%) \\
67(30.9 \%) \\
\end{array}$ & .8409 \\
\hline \multicolumn{4}{|l|}{ Radiologic Factors } \\
\hline $\begin{array}{l}\text { Specific Radiologic Diagnosis at Level of Injection } \\
\text { Central stenosis } \\
\text { Foraminal stenosis } \\
\text { Degenerative disc disease } \\
\text { Disc herniation } \\
\text { Spondylolisthesis } \\
\text { Nerve root impingement } \\
\text { Multiple diagnoses }\end{array}$ & $\begin{array}{c}21(72.4 \%) \\
7(100 \%) \\
22(81.5 \%) \\
37(66.1 \%) \\
4(57.1 \%) \\
91(65.5 \%) \\
190(68.6 \%) \\
\end{array}$ & $\begin{array}{c}8(27.6 \%) \\
0(0 \%) \\
5(18.5 \%) \\
19(33.9 \%) \\
3(42.9 \%) \\
48(34.5 \%) \\
87(31.4 \%) \\
\end{array}$ & .3472 \\
\hline \multicolumn{4}{|l|}{ Procedure Characteristics } \\
\hline $\begin{array}{l}\text { Needle Length (inches) } \\
3.5 \\
5.0 \\
7.0 \\
\end{array}$ & $\begin{array}{c}271(67.8 \%) \\
97(70.8 \%) \\
3(75.0 \%) \\
\end{array}$ & $\begin{array}{c}129(32.3 \%) \\
40(29.2 \%) \\
1(25 \%) \\
\end{array}$ & .7716 \\
\hline $\begin{array}{l}\text { Injectate Volume } \\
\text { Total contrast } \\
\text { Total local anesthetic } \\
\end{array}$ & $\begin{array}{l}1.47(0.76) \\
2.18(0.46) \\
\end{array}$ & $\begin{array}{l}1.48(0.84) \\
2.11(0.35) \\
\end{array}$ & $\begin{array}{l}.9186 \\
.0701 \\
\end{array}$ \\
\hline $\begin{array}{l}\text { Medial \& Superior Contrast Pattern } \\
\text { Yes } \\
\text { No }\end{array}$ & $\begin{array}{c}345(68.2 \%) \\
25(73.5 \%) \\
\end{array}$ & $\begin{array}{c}161(31.8 \%) \\
9(26.5 \%) \\
\end{array}$ & .5158 \\
\hline $\begin{array}{l}\text { Intravascular Uptake } \\
\text { Yes } \\
\text { No }\end{array}$ & $\begin{array}{l}57.9 \%(22) \\
69.6 \%(348)\end{array}$ & $\begin{array}{l}42.1 \%(16) \\
30.4 \%(152)\end{array}$ & .1333 \\
\hline $\begin{array}{l}\text { Trainee Involved } \\
\text { No } \\
\text { Physician } \\
\text { Fellow } \\
\text { Resident } \\
\end{array}$ & $\begin{array}{c}167(64.7 \%) \\
24(77.4 \%) \\
166(71.2 \%) \\
15(75.0 \%) \\
\end{array}$ & $\begin{array}{l}91(35.4 \%) \\
7(22.6 \%) \\
67(28.8 \%) \\
5(25.0 \%) \\
\end{array}$ & .2558 \\
\hline \multicolumn{4}{|l|}{ Reported Pain } \\
\hline $\begin{array}{l}\text { Concordant Pain Provoked during Injection } \\
\text { Yes } \\
\text { No }\end{array}$ & $\begin{array}{l}254(68.1 \%) \\
114(69.5 \%)\end{array}$ & $\begin{array}{r}119(31.9 \%) \\
50(30.5 \%)\end{array}$ & .7449 \\
\hline
\end{tabular}

dial and superior contrast pattern was uncommon at less than $8 \%$, so our study did not have the statistical power necessary to detect differences between various types of spinal pathology by radiologic diagnosis specifically in cases of aberrant flow patterns. Further study is needed.

The strengths of this study include a large sample size, a study sample representative of realistic spine care without any artificial selection of patients, and the prospective collection of data in order to reduce recall bias.
This study is primarily limited by possible selection bias given that patients who did not follow-up in clinic could not be studied, and an incomplete followup rate $(66 \%)$. Multiple physicians performing injections and assessments as well as differing injectate volumes depending on the number of sites selected for treatment contribute to variability in the data; this does increase the generalizability of our findings. Individuals may have received epidural injections prior to the study period, or at an outside facility, but this information was not available in the RICPLAS clinical 
database. Additionally, this study investigated the relationship of various clinical factors to pain-related but not functional, psychometric, or medication use outcomes. Ideally, the study of outcomes of transforaminal ESI should include all of these, but such data were not available. The volume of corticosteroid injected, concentration of lidocaine used, and needle gauge size may also influence the provocation of pain during transforaminal ESI, but there was no variability in these factors across this study sample, so further study will be needed in this regard. Finally, conclusions regarding subacute and long-term pain outcomes cannot be determined from this study as primarily only short-term data were available.

\section{Conclusion}

Provocation of concordant radicular pain does not predict pain relief after a transforaminal ESI. Foraminal stenosis, nerve root impingement, and lack of a medialsuperior contrast flow pattern are associated with pain during the transforaminal ESI. Thus, clinicians should be aware of these radiologic and procedural risk factors for inciting pain during transforaminal ESI.

\section{Disclaimer}

There was no external funding in the preparation of this manuscript.

\section{Conflict of interest}

Each author certifies that he or she, or a member of his or her immediate family, has no commercial association (i.e., consultancies, stock ownership, equity interest, patent/licensing arrangements, etc.) that might pose a conflict of interest in connection with the submitted manuscript.

\section{References}

1. Friedly J, Chan L, Deyo R. Increases in lumbosacral injections in the Medicare population: 1994 to 2001. Spine 2007; 32:1754-176o.

2. Evans W. Intrasacral epidural injection in the treatment of sciatica. Lancet 1930; 219:1225-1229.

3. Steindler A, Luck J. Differential diagnosis of pain in the low back: Allocation of the source of the pain by the procaine hydrochloride method. JAMA 1938; 110:106-113.

4. Tajima T, Furukawa K, Kuramochi E. Selective lumbosacral radiculography and block. Spine (Phila Pa 1976) 1980; 5:68-77.

5. Schutz H, Lougheed WM, Wortzman G, Awerbuck BG. Intervertebral nerve-root in the investigation of chronic lumbar disc disease. Can J Surg 1973; 16:217-221.

6. Krempen JF, Smith BS. Nerve-root injection: A method for evaluating the etiology of sciatica. J Bone Joint Surg Am 1974; 56:1435-1444.

7. Macnab I. Negative disc exploration. An analysis of the causes of nerve-root involvement in sixty-eight patients. J Bone Joint Surg Am 1971; 53:891-903.

8. Falconer MA, Glasgow GL, Cole DS. Sensory disturbances occuring in sciatica due to intervertebral disc protrusions: Some observations on the fifth lumbar and first sacral dermatomes. J Neurol Neurosurg Psychiatry 1947; 10:72-84.

9. Dooley JF, McBroom RJ, Taguchi T, Macnab I. Nerve root infiltration in the diagnosis of radicular pain. Spine (Phila $\mathrm{Pa}$ 1976) 1988; 13:79-83.

10. Van Akkerveeken PF. The diagnostic value of nerve root sheath infiltration. Acta Orthop Scand Suppl 1993; 251:61-63.

11. Stanley D, McLaren MI, Euinton HA, Getty CJ. A prospective study of nerve root infiltration in the diagnosis of sciatica. A comparison with radiculography, computed tomography, and operative findings. Spine (Phila Pa 1976) 1990; 15:540-543.

12. Haueisen DC, Smith BS, Myers SR, Pryce ML. The diagnostic accuracy of spinal nerve injection studies. Their role in the evaluation of recurrent sciatica. Clin Orthop Relat Res 1985; 198:179-183.

13. Herron LD. Selective nerve root block in patient selection for lumbar surgery: Surgical results. J Spinal Disord 1989; 2:75-79.

14. Candido KD, Rana MV, Sauer R, Chupatanakul L, Tharian A, Vasic V, Knezevic NN. Concordant pressure paresthesia during interlaminar lumbar epidural steroidinjections correlates with pain relief in patients with unilateral radicular pain. Pain Physician 2013; 16:497-511.

15. Sinofsky AH, Aydin SM, Kim E, Gharibo CG. Concordant provocation as a prognostic indicator during interlaminar lumbosacralepidural steroid injections. Pain Physician 2014; 17:247-253.

16. Plastaras CT, Heller DS, Sorosky BS, Houle TT. Pain reproduction during lumbosacral transforaminal epidural steroid injection does not affect outcome. Journal of Back \& Musculoskeletal Rehabilitation 2006; 19:57-6o.

17. Perrot S, Laroche F, Marie P, PayenChampenois $C$. Are there risk factors for musculoskeletal procedural pain? A national prospective multicentre study of procedural instantaneous pain and its recall after knee and spine injections. Joint Bone Spine 2011; 78:629-635.

18. Tekaya R, Sahli H, Besghaier L, Saidane O, Abdelmoula L, Chaabouni L, Zouari R. Procedural pain assessment after spinal injections of corticosteroid. Tunis Med 2012; 90:219-222.

19. Park CH, Lee $\mathrm{SH}$. Effect of relative injectate pressures on the efficacy of lumbar transforaminal epidural steroid injection in patients with lumbar foraminal stenosis. Pain Pract 2014; 14:223-227.

20. April C, Bogduk N, Dreyfuss P, Endres S, Govind J, Kraft M, Pauza K, Rogers K, Tibiletti C, Yin W. Practice Guidelines for Spinal Diagnostic ex Treatment Procedures. First Edition. International Spine Intervention Society, 2004. San Francisco.

21. El-Yahchouchi C, Wald J, Brault J, Geske J, Hagen C, Murthy N, Kaufmann T, Thielen K, Morris J, Diehn F, Amrami K, Carter R, Shelerud R, Maus T. Lumbar transforaminal epidural steroid injections: Does immediate post-procedure pain response predict longer term effectiveness? Pain Med 2014; 15:921-928. 